\title{
COVID 19 PANDEMIC AND HEALTHCARE SECTOR IN NORTH MACEDONIA: WHAT HAS CHANGED FOR THE HUMAN RESOURCE MANAGEMENT
}

\author{
Ljupco Eftimov \\ Faculty of Economics - Skopje, Ss Cyril and Methodius University \\ eftimov@eccf.ukim.edu.mk \\ Tihona Bozhinovska \\ Faculty of Economics - Skopje, Ss Cyril and Methodius University \\ tihonabozhinovska@gmail.com
}

\begin{abstract}
The way the employees in the health care sector were managed during the period 2020-2021 was crucial for the management of the overall social and economic crisis. The most important areas from strategic human resource management that needed urgent attention during COVID 19 pandemic were: appropriate communication of the requirements of the new normal and identification of the most skillful employees for adapting to the changes and forecasting the forthcoming trends. Therefore, investigating the key activities for increasing the healthcare providers satisfaction of human resource management process during Covid 19 is an important issue and can offer significant insights for HR professionals and for the healthcare organizations. The purpose of the paper is to shed some light on the most important human resource practices during the COVID 19 pandemic and to understand how healthcare organizations had to rethink their approaches in order to maintain the motivation and commitment of the healthcare providers. The capability and willingness of the healthcare staff to stay focused and to cooperated in a dynamically changing internal and external environment was crucial for the overall healthcare sector during the pandemic. Hence, this study is trying to contribute by: identifying the key human resource (HR) issues/challenges in healthcare organizations during the pandemic, creating a theoretical model of strategic human resource management during Covid 19 in healthcare organizations and understanding which human resource (HR) practices/activities were perceived as most important for increasing healthcare providers satisfaction of the human resource management process in their organizations during the last period of turmoil.
\end{abstract}

Key words: human resource management, pandemic, healthcare providers satisfaction of HRM, healthcare sector, key activities.

JEL Classification: M12, M54

\section{INTRODUCTION}

Covid 19 pandemic has created a real crisis in the healthcare sector and in the overall economy during 2020 and 2021. The most important areas from strategic human resource management that needed urgent attention during this period were: reweaving crisis plan in the parts related to possibilities for suitable replacement of absent team members, appropriate communication of the requirements of the new normal, detecting the most skillful employees for adapting to the changes and forecasting the forthcoming trends. This pandemic one more time showed the importance of implementing strategic and agile human resource (HR) management which refers 
to the organization's ability to "maintain the relationship between its HR assets and the methods, objectives, strategies, and ultimate goals of all company assets" (Ichsan et al, 2020, p. 13099).

Several studies are investigating the challenges imposed to the healthcare providers/workers by the uncertain trajectory of Covid 19. According to Sengupta at al. (2021), the key challenges faced by the healthcare personnel during the Covid 19 pandemic can be divided in two groups: 1. workplace challenges which includes: resource availability, adequacy and allocation, financial issues, perceived managerial ineffectiveness, inconsistent guidelines and perceived occupational stress; and 2. societal/community challenges which includes: dread disease, social adaptiveness and challenges related to essential services. Gordon et al. (2020) argues that challenges with personal protective equipment, long shifts, and changes in regular routines placed tremendous stress on health care workers during this period. Ness et al. (2021) have defined four themes related to Covid 19 challenges for healthcare providers: managing isolation, fear, and increased anxiety; adapting to changes in healthcare practice and policy; addressing emotional and physical needs of patients and their families; and navigating evolving workplace safety. In this circumstances retention of the key healthcare providers is one of the most important tasks of the human resource managers and the administration of the healthcare organizations. Jamebozorgi et al. (2021), have noted that "retention of human resources, especially in the health sector, is more important in disasters than in any other time, because an organization's human resources should not only work against disastrous threats such as disease outbreaks, but also have to encounter new underlying problems" (p.3). Rangachari and Woods (2021) have argued "how a stoic approach to healthcare worker support during the Covid 19 pandemic has the potential to restrict organizational resilience, and adversely impact patient safety and staff retention during and beyond the pandemic period" (p.9). Therefore, investigating the key activities for increasing healthcare providers satisfaction of HRM during Covid 19 is an important issue and can offer significant insights for HR professionals and for the organizations implementing strategic and agile HR management.

In line with this, the purpose of the paper is to shed some light on the most important human resource practices during the Covid 19 pandemic and to understand how healthcare organizations had to rethink their approaches in order to maintain the motivation and commitment of the healthcare providers. This study is trying to contribute by identifying the key human resource (HR) issues during the pandemic, creating a theoretical model of strategic human resource management during Covid 19 in healthcare organizations and understanding which human resource (HR) practices were perceived as most important for increasing healthcare providers satisfaction of human resource management process during the period of turmoil.

\section{PREVIOUS RESEARCH AND HEALTHCARE SECTOR IN NORTH MACEDONIA}

\subsection{Key changes for HRM in healthcare organizations during COVID 19}

Carnevale and Hatak (2020), have systematized the HRM challenges and opportunities during Covid 19 which include: the erosion of "fit"- involves adjusting new and current employees to drastically altered work conditions; disproportionate work-family effects- understanding the impact the extreme family demands in conjunction with heightened levels of work autonomy and thereby self-responsibility can have on employees' productivity and well-being, and which practices can alleviate such new avenues of family to work conflict, will be important; and disproportionate effects on alternative family structures-the grand challenge of our current health crisis is likely to illuminate vulnerabilities in an increasingly relevant, yet understudied, segment of contemporary family structure: childless and single employee. 
Stuart et al. (2021), argued that Covid 19 crisis one more time showed that job retention should be a central aim and practice of human resource management (HRM). Furthermore, it is noted that "if the crisis is to generate any benefit it must create the conditions for a more collaborative HRM that delivers for workers as well as business, with job retention as a core priority" (p. 1). In regard to the researches of employee retention in the pre Covid 19 era it was noted that most of them approached employee retention using a group of individual factors such as employee motivation, job satisfaction, and organizational culture (Kossivi et al., 2016).

Although the described roles and challenges of the HR management are important for every industry/sector, the healthcare sector was on the front line during this pandemic. Consequently, in the following part we are going to make brief overview of the studies focused on human resource management roles in healthcare organizations during the pandemic.

Rangachari and Woods (2020), have given two recommendations for the healthcare organizations leaders in order to "preserve resilience, patient safety, and staff retention during and beyond the Covid 19 pandemic: 1. create an environment of trust, psychological safety, and empowerment to enable individual workers to communicate patient safety concerns to managers; 2. develop communication structures to enable the organization to learn from the problem-solving strategies and communications of individual healthcare workers" (p. 10).

Sengupta et al. (2021), conducted individual in-depth interviews on 20 healthcare providers and classified the challenges of healthcare staff during Covid 19 into workplace and societal/community challenges. "Workplace challenges included resource availability, adequacy and allocation, financial issues, perceived managerial ineffectiveness, inconsistent guidelines and perceived occupational stress, while societal/community challenges included dread disease, social adaptiveness and challenges related to essential services" (p. 339).

Abdullah et al. (2021) conducted a study on 250 nurses of different private hospitals and found that "nurses' job satisfaction in hospitals could be ensured through social and psychological rewards while considering work demand and work-family conflict as an independent variable while considering the Covid 19 pandemic situation as a huge influencer" (p. 9).

Brugha (2021) has noted that "young doctors especially are pulled towards the opportunities of life experiences and comparatively better training in other countries; and pushed by negative experiences while working and training in their country of graduation". Furthermore, this author gives a deepening analysis of Irich doctors' emigration and notes that reasons for leaving of young doctors include: unsatisfactory working conditions, lack of supervision and mentoring, and their comparatively poor training experiences. Additionally, the study of Humphries et al. (2021) done with qualitative interviews on a sample of 31 hospital doctors in Ireland has shown that the pandemic intensified and reinforced, rather than radically altered, the dynamics of doctor emigration from Ireland. They also argue that "persistent emigration is usually the symptom, not the cause, of an underlying problem and is the result of a range of interacting factors which each exacerbate the other" (p. 7).

Elsafty and Ragheb (2020) have conducted research on employees in healthcare industry, more specifically from the medical supplies sector, and found that health related and quality of life and access to information and updates on the Pandemic with financial benefits are the most important variables to the retention of employees (p.57).

Furthermore, Jamebozorgi et al. (2021) conducted a systematic review of 23 articles related to coronavirus impact on health workers retention and synthetized the effects of Covid19 on hospital staff and the retention strategies used by the HR managers and senior management. According to Jamebozorgi et al. (2021) the most significant effects of Covid 19 on hospital staff include: violence and stigma against the staff, burnout and stress and increased employee workloads, while the retention strategies include: acquiring communication skills, attention to employees mental and physical health, attention to employee's safety, mobilizing the staff to 
assist the current forces, expanding cyberspace infrastructures and motivational-health incentives.

According to the analyzed literature, the key challenges for human resource management in healthcare organizations during the Covid 19 pandemic can be systematized as presented in Table 1.

Table 1 Challenges for Human Resource Management during the pandemic

\section{Challenges for Human

Resource Management during Author/Authors Description

\begin{tabular}{|c|c|c|}
\hline The erosion of "fit" & $\begin{array}{l}\text { Carnevale and } \\
\text { Hatak }(2020) ;\end{array}$ & $\begin{array}{l}\text { Involves adjusting current and new employees to } \\
\text { drastically altered work conditions. }\end{array}$ \\
\hline Work overloads & $\begin{array}{l}\text { Jamebozorgi et al. } \\
(2021) \text {; }\end{array}$ & $\begin{array}{l}\text { Healthcare providers face work overloads even in } \\
\text { non-pandemic times. However, the speed in which } \\
\text { the number of infected patients increased in some } \\
\text { periods during the crisis intensified the occurrence } \\
\text { of work overloads. }\end{array}$ \\
\hline
\end{tabular}

Inconsistent guidelines Sengupta et al. During the pandemic the information regarding the (2021); dieses/virus have been changing rapidly and therefore the preparation of formal, step-by-step guideline on time was challenging. This also referees to the absence of standardized testing kits, protocols and resource materials, training of staff.

Health related and quality of life Carnevale and Attention to healthcare providers safety, issues (work-family balance) Hatak (2020); preparedness towards infection control, attending Abdullah et al. the need of the healthcare providers infected with (2021); the virus, understanding the effect of possible Jamebozorgi et al. work-family conflict imposed by the new (2021); Sengupta et circumstances. Additionally, in these al. (2021); circumstances healthcare providers are more prone to occupational stress and during the pandemic the pressure and the occurrence of burnout increases.

\begin{tabular}{|c|c|c|}
\hline Retention of staff & $\begin{array}{l}\text { Jamebozorgi et al. } \\
\text { (2021); } \\
\text { Rangachari and } \\
\text { Woods (2020); } \\
\text { Brugha (2021); } \\
\text { Humphries et al. } \\
\text { (2021); } \\
\text { Stuart et al. (2021). }\end{array}$ & $\begin{array}{l}\text { Humphries et al. (2021) have noted that "the } \\
\text { pandemic intensified and reinforced, rather than } \\
\text { radically altered, the dynamics of doctor emigration } \\
\text { from Ireland", while Jamebozorgi et al. (2021) and } \\
\text { Rangachari and Woods (2020) are more focused on } \\
\text { strategies and recommendations for staff retention. } \\
\text { Nevertheless, this crisis showed that the retention } \\
\text { of the most skillful staff should be a central aim of } \\
\text { every organization, especially in the healthcare } \\
\text { sector. However, this requires continuous effort } \\
\text { from the organizations' management. }\end{array}$ \\
\hline
\end{tabular}

Source: Authors' construction

\subsection{COVID 19 pandemic and healthcare sector in North Macedonia}

The healthcare sector in Republic of North Macedonia has faced significant number of challenges from the beginning of the Covid 19 pandemic. The pressure created by the pandemic uncovered the weakness in the management of healthcare organizations, whether public or private.

According to the data available it can be noted that total number of coronavirus infected individuals had a peak in med-December 2020 and afterwards it started to drop (OECD, 2021). It is expected new increase in the number of infected individuals to occur by the end the year, 
since vaccine coverage (the percent of individuals that received at least one dose of a vaccine) is around $39 \%{ }^{1}$.

In order to respond suitably to the new conditions, the management of the healthcare organizations attempted to ensure sufficient physical infrastructure and to increase the workforce capacity. The process of increasing the workforce capacity in a condition when the medical staff is facing unprecedented levels of work overloads and the young doctors were transferred from the hospital in which they were on education/tanning into the organizations that needed more medical staff (Covid 19 centers, which means that their educational activities had to be paused on a limited period, several months), from the perspective of the strategic human resource management has been challenging. It can be noted that the management of the healthcare organizations in Republic of North Macedonia has faced the same challenged as described in the other countries, summarized as follows: the erosion of "fit", work overloads, inconsistent guidelines, health related and quality of life issues and retention of medical staff. Additionally, the management of the healthcare organizations had to acknowledge the abrupt changes in the workplace features, their influence of the healthcare providers roles in the organizations and to understand theirs job-related attitudes, in order to increase their capacity to adequately respond to the new and incremented requirements. Therefore, in the following part this paper offers and overview of the key steps of the strategic human resource management in the healthcare organizations during the pandemic and explains the theoretical background for researching the antecedents of the job-related attitudes, in order to be able to examine the healthcare providers satisfaction of human resource management in the Macedonian context.

\section{THEORETICAL BACKGROUND}

\subsection{Proposed model of strategic human resource management in healthcare organizations during the pandemic}

Since the early 1990s human resource management has expand to developing paths career for employees, ensuring employees safety and health, managing employee's diversity and managing human capital issues which emphasized the importance of HRM for organizational performance and the link with organizational strategy (Fottler et al. (ed), 2010). During the pandemic the strength of this links has been tested. Namely, the period of crisis uncovers that the weaknesses in the links between the human resource management and organizational strategies can have undesired effects on the organizational performances. Organizations implementing strategic human resource management support proactive behaviors and have well established communication channels, which enables the gap between the current situation and the vision of the future to be timely and adequately addressed. Collings et al. (2021) have identified three substantive implications for strategic HRM research during the pandemic: 1 . the pandemic highlights a need to expand understanding about how work context influences employee behaviors and actions; 2. it exposes tensions among stakeholders, highlighting the need to consider inter alia employees, customers, and communities along with shareholders; and 3. tensions between the strategic and operational roles of HR are exposed (p. 5).

The main characteristics of the healthcare organizations are that they are service-orientated and knowledge-based institutions (Khatri et al., 2015). The key features of healthcare organizations include:

- They provide a complex service for the patients (Thompson at al., 2012),

- The employees in the healthcare organizations have greater discretion in meeting the needs of the patients (Khatri et al., 2015),

\footnotetext{
${ }^{1}$ Data available at: https://covid19.healthdata.org/north-macedonia?view=vaccinations\&tab=trend
} 
- Significant part of the organizational knowledge is housed exclusively in the minds of the employees (Khatri et al., 2015),

- Coordination and team work between highly specialized disciplines is crucial for executing complex tasks for meeting patients' needs (Thompson at al., 2012), and

- The patients' satisfaction is mediated by employees' satisfaction (Khatri et al., 2015).

Human resource management plays strategic role in delivering high quality and affordable health care Fottler et al. (ed) (2010) and sequentially it is a fundamental, rather than supportive function in the health care, crucial for enhancing healthcare organization performances (Khatri et al., 2015). Fottler (2011) has systematized the most effective HRM practices for healthcare organizations into five (5) categories:

1. HR planning/Job Analysis - encourage employee involvement so there is strong "buy-in" of HR practices and managerial initiatives; encourage teamwork; provide employment security; include self-managed teams; develop strategies to enhance employee work/life balance;

2. Staffing - proactiveness in identifying and attracting talent; in selecting new employees, use additional criteria beyond basic skills;

3. Training/ Organizational Development - invest in training; provide employees with future career opportunities; include customer service in new employee onboarding and skill development; provide opportunities for employee growth;

4. Performance Management and Compensation - recognize employees by providing monetary and nonmonetary rewards; offer high compensation contingent on organizational performance; reduce status distinction and barriers;

5. Employee Right - communicate effectively with employees to keep them informed concerning major issues and initiatives; share financial, salary, and performance information to develop a high-trust organization; provide employment security for employees who perform well so they are not downsized because of economic downturns or strategic errors by senior management.

Regardless of the importance of human resource for achieving high quality patient care, there is a general conclusion that they are not particularly well managed in healthcare organizations (Khatri et al., 2015). Furthermore, Khatri et al., 2015) argue that HRM should be involved in organizational change efforts to foster and grow interprofessional collaboration and teamwork, which was extremely important during the pandemic when doctors from different specialistic areas had to care and facilitate healing of patients with Covid 19. Therefore, in the Figure below this paper offers an overview of the key steps that should/have been undertaken by healthcare organizations implementing strategic human resource management during the Covid 19 pandemic. The pandemic imposed the need for rapid adaptation to the newly arisen circumstances and undertaking steps for proactive behavior by the healthcare providers in order to implement the required changes as soon as possible and maintain the desired level of service quality. The process of strategic human resource management in the healthcare organizations during the Covid 19 pandemic included the steps described in Figure 1.

This model explains the strategic role of human resource management in healthcare organizations during the pandemic. Namely, the process of strategic management of human resource in healthcare organization during the pandemic includes:

1. Scanning the environment - in this step the most important issues were related to analysis of the development of the pandemic (the expected number of newly infected cases, their expected clinical manifestations and the need for hospitalizations), as well as analysis of the number of healthcare workforce (number of specialists, number of general doctors, number of nurses and other medical and non-medical staff) and their capabilities beyond the basic skills (such as capacity for collaboration, adaptation, proactive behavior). 
2. Defining and understanding the key changes that had to be implemented in order to adapt to the newly arisen conditions and the main implications for healthcare staffthis step involves defining needed reorganizations (transforming the hospitals/clinics fully or partially into Covid 19 centers, transferring doctors from different specialties to work on providing healthcare for Covid 19 patients, asking young doctors to pause their educational process/trainings for several months), as well as the expected changes in the behaviors of the healthcare staff during this pandemic period and how the intended changes are expected to impact individual, team and overall organizational performances.

Figure 1 Strategic human resource management activities during Covid 19 in healthcare organizations

\begin{tabular}{|c|c|c|c|}
\hline $\begin{array}{l}\text { Fast scanning of the } \\
\text { dynamically } \\
\text { changing } \\
\text { environment (both } \\
\text { external and } \\
\text { internal) and } \\
\text { forecasting } \\
\text { upcoming trends in } \\
\text { regard to the } \\
\text { pandemic. Analysis } \\
\text { of the number of } \\
\text { healthcare } \\
\text { workforce and their } \\
\text { capabilities beyond } \\
\text { the basic skills is } \\
\text { crucial. }\end{array}$ & $\begin{array}{l}\text { Defining and } \\
\text { understanding the } \\
\text { key changes that has } \\
\text { to be implemented in } \\
\text { order to adapt to the } \\
\text { newly arisen } \\
\text { conditions and the } \\
\text { main implications } \\
\text { for healthcare staff } \\
\text { (how the intended } \\
\text { reorganizations are } \\
\text { going to influence } \\
\text { healthcare } \\
\text { providers, the level } \\
\text { of collaboration and } \\
\text { team work) }\end{array}$ & $\begin{array}{l}\text { Identifying the } \begin{array}{l}\text { key } \\
\text { activities } \\
\text { increasing } \\
\text { staff }\end{array} \\
\text { preparedness and } \\
\text { motivation for } \\
\text { adaptation and for } \\
\text { upcoming changes, } \\
\text { as well as } \\
\text { identifying the key } \\
\text { employees for } \\
\text { leading the process } \\
\text { of adaptation and } \\
\text { change }\end{array}$ & $\begin{array}{l}\text { Effective support of } \\
\text { the adaptation and } \\
\text { implementation of } \\
\text { changes through: } \\
\text { - Proper } \\
\text { communication of } \\
\text { organizational } \\
\text { issues and staff } \\
\text { health-related } \\
\text { issues emerged } \\
\text { during the } \\
\text { pandemic to } \\
\text { - Asses } \\
\text { information th } \\
\text { regarding } \\
\text { pandemic } \\
\text { - Support } \\
\text { implementing for } \\
\text { workplace } \\
\text { guidelines }\end{array}$ \\
\hline & & & \\
\hline
\end{tabular}

Source: Authors' construction

3. Identifying the key activities for increasing staff preparedness and motivation for adaptation and for upcoming changes, as well as identifying the key employees for leading the process of adaptation and change is also an important step. In order to properly manage the human resources available, the healthcare organizations had to identify the activities that are going to increase the level of commitment, the loyalty and the motivation of the staff in order to achieve the organizational goals and help them in the process of adaptation to the drastically altered work conditions. In this step the identification of the key employees for leading the process of change and adaptation is also important.

4. The last step is effective support of the adaptation and implementation of the required changes through proper communication of organizational issues, asses to information regarding the pandemic and support for implementing workplace guidelines. In this study we evaluate that these activities are important for the effective support of the processes of adaptation and change:

- proper communication of organizational and staff health-related issues emerged during the pandemic, such as: resource availability, adequacy and allocation, 
perceived ineffectiveness, unbalanced workload in a team, occupational stress, stigma against the staff etc. Additionally, healthcare organizations had to be more alert to their staff health and increase their preparedness towards infection control, which can be challenging from organizational aspect. Therefore, proper communication of staff health related issues that can have organizational implications is also important.

- asses to information regarding the pandemic - healthcare organizations are knowledge based and as such they have to find mechanisms for dissemination of crucial information regarding the pandemic to the employees and accumulating knowledge gained through practice.

- support for implementing workplace guidelines - one of the key challenges for human resource management during the pandemic was the existence of inconsistent guidelines (Sengupta et al., 2021). Since there has been an absence of standardized protocols and training of staff, the individuals responsible for strategic human resource management during Covid 19 pandemic must be open for any kind of support and explanation regarding the implementation of the existent guidelines. This is important for achieving desired levels of individual and organizational effectiveness.

This model offers a dynamic approach to strategic HRM during the pandemic (since the information accumulated in each of the phases should be transferred and adequately used in the other phases/steps), and explains how the roles of human resource management in healthcare organizations have evolved in the context. The model intends only to describe the activities that had to be undertaken in order to link the human resource management to the process of implementing the imposed adaptation and changes that were necessary for achieving the ultimate goal of the healthcare organizations - delivering healthcare services to the patients. Additionally, in the process of the strategic human resource management during the pandemic, in both public and private healthcare organizations, the management structures on every level should be included, and not just the HR professionals or HR unit/department. This process in a specific working condition imposed by the pandemic, must be understood by all the management structures. The model presents author's interpretation of the steps in the strategic HRM in the specific context created in the healthcare organizations during the pandemic.

Considering the fact that healthcare organizations are service-orientated, the satisfaction of the healthcare providers is crucial for healthcare delivery process and has significant impact on the patient's satisfaction level. Furthermore, Collings et al. (2021) have suggested that the pandemic highlights a need to expand the understanding about how work context influences employee behaviors and actions. The model describes the activities of human resource management that had to be undertaken in order to facilitate the process of adaptation of the healthcare providers to the drastically altered working conditions and the process of implementing the imposed changes during the pandemic period. In the following part, the study is trying to identify how the activities that are part from the strategic HRM process are perceived by the healthcare providers and do they have an impact to the healthcare staff job-satisfaction, which is related to healthcare providers' behavior and retention.

\subsection{Antecedents of job attitudes/job satisfaction}

Several theoretical approaches have discussed the antecedents of job-attitudes, as well the antecedents of job-satisfaction. The research of the factors affecting the formation of jobattitudes, which also includes job-satisfaction, is important because from a psychological point of view attitudes are related to specific behaviors (Ajzen, 1991; Judge et al, 2012). Judge at al. (2012) have concluded that the studies investigating the relations between job-satisfaction and specific behaviors have generated a set of generally positive results. In order to support this 
statement Judge at al. (2012) have cited several empirical studies that examine the relation between job-satisfaction and specific job-behaviors, such as: "attendance at work (Smith, 1977; Scott \& Taylor, 1985); turnover decisions (Carsten \& Spector, 1987; Hom, Katerberg \& Hulin, 1979; Hom 2001; Hulin, 1966; 1968; Mobley, Horner, \& Hollingsworth, 1978; Miller, Katerberg, \& Hulin, 1979); decisions to retire (Hanisch \& Hulin, 1990, 1991; Schmitt \& McCune, 1981); psychological withdrawal behaviors (Roznowski, Miller, \& Rosse, 1992); pro-social and organizational citizenship behaviors (Bateman \& Organ, 1983; Farrell, 1983; Roznowski, Miller, \& Rosse, 1992), union representation votes (Getman, Goldberg, \& Herman, 1976; Schriesheim, 1978; Zalesny, 1985); hostile or punitive behaviors directed towards coworkers or supervisors (Hershcovis, Turner, Barling, Arnold, Dupré, Inness, LeBlanc, \& Sivanathan, 2007); customers' perceptions of the service provided by employees (Snipes, Oswald, LaTour, and Armenakis, 2005)" (p. 6-7).

In regard to the antecedents of job-satisfaction, as an important attitude that drives the employees' behavior in every organization, Fritzshe and Parrish (2005) have given an in-depth overview. Namely, Fritzshe and Parrish (2005) have systematized the antecedents of jobsatisfaction in 6 (six) categories and their analysis is presented in Table 2. From the Table it can be noted that different theoretical approaches give different explanation about the process of forming job-related attitudes by the employees. Some authors acknowledge the importance of the situational factors such as: social context (Salancik and Pfeffer, 1978), job characteristics (Hackman and Oldham, 1976), job stressors (Fairbrother and Warn, 2003), leadership (Fiedler, 1967) while others outline the importance of the personal characteristics, such as the personal disposition (George, 1992; Judge and Locke, 1993) for the process of forming job-related attitudes. The main conclusion from the brief overview is that the antecedents of job-related attitudes include both situational factors, as well as individual characteristics of the employees. Consequently, the principal implication for empirical research is that in the investigation of employees' attitudes different antecedents should be included.

Table 2 Antecedents of job attitudes/job satisfaction

\begin{tabular}{|c|c|c|}
\hline $\begin{array}{l}\text { Antecedent of job } \\
\text { satisfaction/job } \\
\text { attitudes } \\
\end{array}$ & $\begin{array}{l}\text { Theoretical and } \\
\text { research } \\
\text { approach }\end{array}$ & Description \\
\hline $\begin{array}{l}\text { Comparison to prior } \\
\text { job-experiences }\end{array}$ & $\begin{array}{l}\text { The Cognitive } \\
\text { Judgement } \\
\text { Approach }\end{array}$ & $\begin{array}{l}\text { Job-satisfaction depends on an evaluation of a difference between } \\
\text { an individuals' expectations and what he/she actually receives. A } \\
\text { Comparison Level (CL) is developed and used as a standard } \\
\text { against which the satisfaction with the current role is evaluated. }\end{array}$ \\
\hline $\begin{array}{l}\text { The social context of } \\
\text { work }\end{array}$ & $\begin{array}{l}\text { Social } \\
\text { Information } \\
\text { Processing } \\
\text { Theory }\end{array}$ & $\begin{array}{l}\text { Social context influences job attitudes formation. There are two } \\
\text { primary ways in which the social context influence attitudes: } 1 \text {. } \\
\text { social context help people form their attitudes; } 2 \text {. social context } \\
\text { help people focus attention on attitude relevant information. }\end{array}$ \\
\hline Job characteristics & $\begin{array}{l}\text { The Job } \\
\text { Characteristics } \\
\text { Approach }\end{array}$ & $\begin{array}{l}\text { Aspects of the work environment impact work outcome, such as } \\
\text { job satisfaction. This approach offers specific ways in which jobs } \\
\text { can be redesigned to be more satisfying. }\end{array}$ \\
\hline Job stressors & $\begin{array}{l}\text { Work and Role } \\
\text { Stressors }\end{array}$ & $\begin{array}{l}\text { A number of other characteristics of the work environment, } \\
\text { generally called workplace and work role stressors, have been } \\
\text { shown to influence job satisfaction. Job stressor may be poor } \\
\text { physical conditions, while role stressors are role ambiguity, role } \\
\text { overload and role conflict. According to job stress models job } \\
\text { stressors lead to short-term and long-term consequences, typically } \\
\text { called strains. }\end{array}$ \\
\hline $\begin{array}{l}\text { Personal } \\
\text { dispositions }\end{array}$ & $\begin{array}{l}\text { The dispositional } \\
\text { approach }\end{array}$ & $\begin{array}{l}\text { According to this approach persons' disposing can be a significant } \\
\text { determinant of his/her job attitudes. Some authors argued that, if } \\
\text { individuals are consistent in their job satisfaction across both time } \\
\text { and context, then the source of this consistency would likely be an } \\
\text { enduring characteristic of the individual. Subsequent research }\end{array}$ \\
\hline
\end{tabular}




\begin{tabular}{|c|c|c|}
\hline & & $\begin{array}{l}\text { attempted to more directly tap dispositional variables (e.g., with } \\
\text { measures of positive affect) in efforts to predict job attitudes and } \\
\text { performance over time. (Staw and Cohen-Carash, 2005) }\end{array}$ \\
\hline $\begin{array}{l}\text { Person-environment } \\
\text { fit }\end{array}$ & $\begin{array}{l}\text { Person- } \\
\text { environment fit } \\
\text { approach: Theory } \\
\text { of } \quad \text { work } \\
\text { adjustment and } \\
\text { Holland's } \\
\text { RIASEC theory }\end{array}$ & $\begin{array}{l}\text { Rather than searching for specific environmental of personality } \\
\text { characteristics that contribute to job-satisfaction, the person- } \\
\text { environment fit approach posits that job satisfaction is influenced } \\
\text { by the extent to which good compatibility exists between people } \\
\text { and their working environment. Thus, situational variables } \\
\text { interact with personal variables to produce job satisfaction. }\end{array}$ \\
\hline
\end{tabular}

Source: Fritzshe and Parrish (2005) and Staw and Cohen-Carash (2005)

Additionally, Judge at al. (2012) analyze the more important models of job attitudes and discuss the recent developments. Models proposed by Judge at al. (2012) that attempt to account the antecedents and complexity of job attitudes, could be used in the research of antecedents of jobsatisfaction. One of the most suitable models for understanding the nature and investigating job attitudes/job-satisfaction proposed by these authors is presented on Figure 2, which represent a model of their interpretation of the affective events theory. The Figure 2 present how Judge at al. (2012) have interpreted and modified the affective events theory, which was primary developed by Weiss and Copanzano (1996). The model basically explains that the antecedents of job attitudes include the feature of the work environment and the job events. Judge at al. (2012) note that job features and job events should be treated as fuzzy sets, and that the second ones are more transient and less predictable. Job features (e.g., HR policies/practices) are more stable and are likely to influence distributions of job events. Furthermore, Judge at al. (2012) define job satisfactions as "multidimensional psychological responses to one's job" (p.5) with two components: the cognitive (evaluative) and the affective (emotional), which are inseparable. These authors also argue that "job performance comprises many specific behaviors typically measured through a subjective supervisory evaluation" and "...that the more "discretionary" or "contextual" - rather than task-oriented-aspects of job performance are driven primarily by motivational processes, including job attitudes" (p. 14). Although the behaviors in the model are divided into judgment- and affect-driven, they should be treated as fuzzy sets, since one strict classification of the job behaviors into one or the other category it is not always applicable (p. 37). In this model personality (personality traits of the individual) is included "... as a moderator of both the cognitive, between-individual links and the affective, within-individual links" (p.43). 


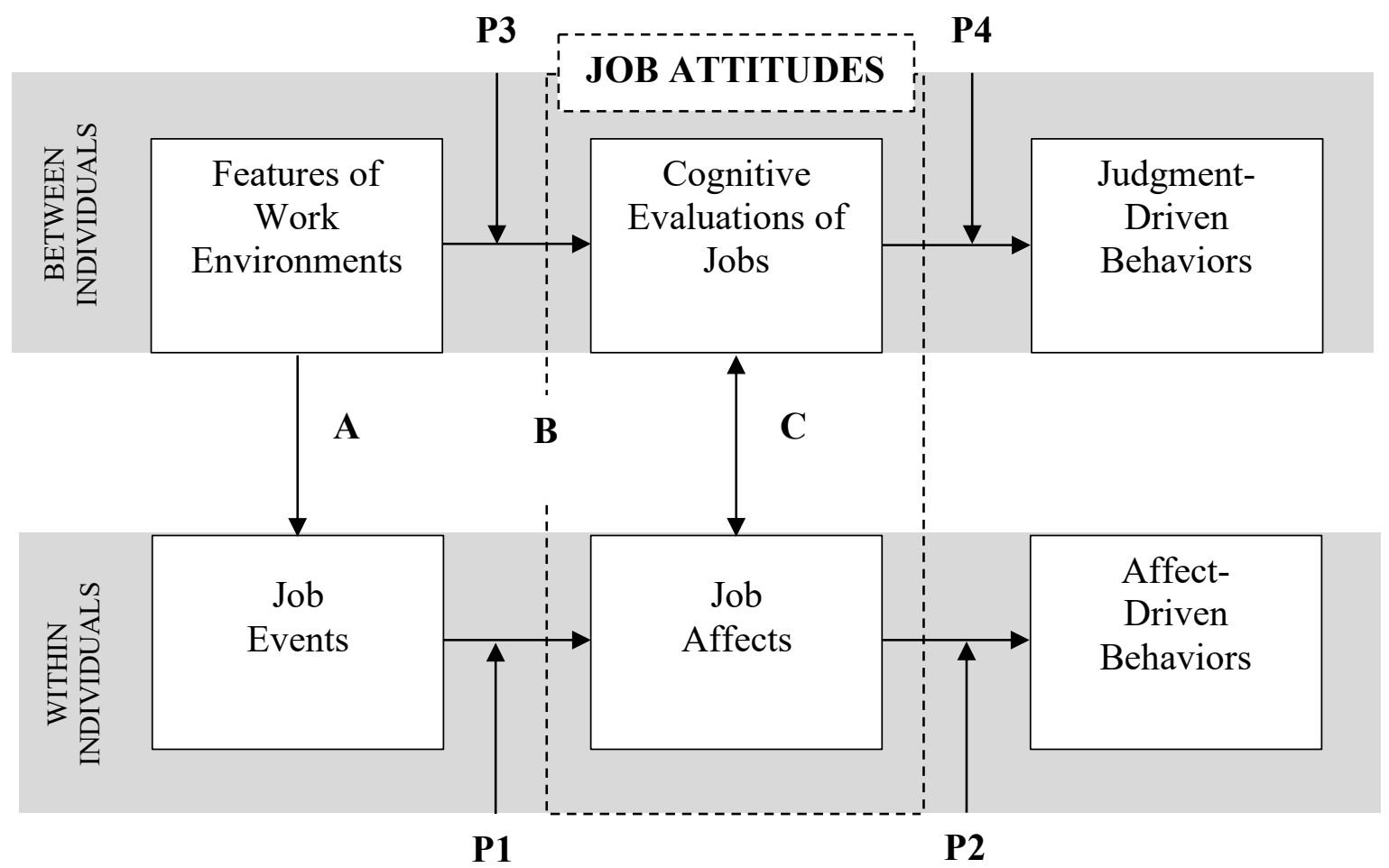

A: Influence on distribution of events

B: Fuzzy boundaries between events and features of work environments

C: Reciprocal relationship between cognition and affect

P: Personality variables as moderators of between- and within-individual relationships

Source: Judge at al. (2012)

Figure 2 Modified version of affective events theory

\section{METHODOLOGY}

Having in mind the importance of healthcare providers satisfaction during Covid 19 pandemic, this paper is trying to understand the complex relation between implemented human resource management practices and the employee's satisfaction from the human resource management in the healthcare organizations. In order to investigate the relation this study uses the methods of correlation and hierarchical linear regression. The regression method for investigating the employees' job-satisfaction in hospitals was used in several previous studies such as Lock and Crawford (2001) and Giauque (2014). The study includes the perceived importance by the healthcare providers of the following activities: support for implementing workplace guidelines, asses to information regarding the pandemic and communication for overcoming the organizational issues as independent variables, which represent features of the work environments. In the model the variables are measured on a 5-point Likert scale. Additionally, we have infused control variables (such as age, gender, position and providing financial benefits). The dependent variable is defined as employees' satisfaction of human resource management and basically represents a job-related attitude that has been formed by the employees in the healthcare organizations.

The developed research hypothesis include: 
H1: Support for implementing workplace guidelines influences the employees' satisfaction of human resource management.

$\mathrm{H} 2$ : Access to information regarding the pandemic influences the employees' satisfaction of human resource management.

H3: Communication for overcoming organizational issues emerged during the pandemic influences the employees' satisfaction of human resource management.

H4: Other factors influence the employees' satisfaction of human resource management.

H4a: Demographic characteristics influence the employees' satisfaction of human resource management.

H4b: Financial benefits influence the employees' satisfaction of human resource management.

Figure 3 Model proposed for testing the hypothesis

\begin{tabular}{|l|l|}
\hline Control variables: \\
Demographic variables \\
$-\quad$ Age \\
$-\quad$ Gender \\
- Position (doctor) \\
Perceived importance of \\
providing $\quad$ Financial \\
Benefits \\
\\
\end{tabular}

Source: Model proposed for testing the hypothesis

\subsection{Research sample}

The sample consists of 82 healthcare providers from public and private healthcare organizations. The total number of distributed questionnaires was 120 and the total number of completely answered questionnaires was 82 , which means that the overall response rate was $68,33 \%$.

According to the data published, the total number of healthcare workers in all healthcare organizations is 33,544 , out of which 6,468 are doctors (and 3,882 of them are specialists), 1,796 are dentists, 1,057 are pharmacists, 18,438 are other medical staff and 5,785 are nonmedical staff (Center for public health - Skopje, 2020, p. 7). According to the same source the total number of employees in the private healthcare organizations (including private hospitals) is 11,753 (Center for public health - Skopje, 2020, p. 7). 
In regard to the structure of the sample of respondents, it can be noted that the $46(56,09 \%)$ of the respondents were physicians, $29(35,37 \%)$ were nurses and only $7(8,54 \%)$ were other hospital staff.

\subsection{The questionnaire and measures}

The questionnaire had two parts: the first part was related to gathering demographic information for the respondents, while the second part was related to measuring employees' satisfaction of HRM, support for implementing workplace guidelines, asses to information about the pandemic, financial benefits, support in health-related and quality of life issues and communication on organizational issues emerged during the pandemic. The total number of items in the questionnaire was 16 . However, in order to meet the assumption of non-existence of multicollinearity every single variable was measured directly (only with one item). The support for implementing workplace guidelines, the asses to information, financial benefits, as well as communication on pandemic issues and employees' satisfaction of HRM were measured directly, with one item through 5-point Likert scale. The dependent variable employees' satisfaction of HRM was also measured with a single item and on a 5-point Likert scale. Giauque (2014) have also used one item for measuring job-satisfaction, and also Elsafty and Ragheb (2020) measure several variables with only one item.

Additionally, we would mention that for gender, dummy variable is created and the respondents are divided in two groups: 0 -male and 1-female. For the position (doctor), it was also created a dummy variable in which the respondents were divided in two groups: 0-for nurses and other staff and 1-for doctors. The data regarding the age of the respondents was performed into a ratio scale variable, where the respondents were classified in 5 categories: below or equal to 30 years, 31-40 years, $41-50$ years, 51-60 years, above 60 years. The other variables were measured on a 5-point Likert scale. The descriptive statistics of the variables are presented in Table 3.

Table 3 Descriptive statistics of the variables

\begin{tabular}{lcc}
\hline Variable & Mean & Std. Dev. \\
\hline Employee's satisfaction of HRM & 3.963 & 1.170 \\
\hline Financial Benefits & 4.350 & 0.837 \\
\hline Support for implementing workplace guidelines & 4.230 & 0.634 \\
\hline Access to information regarding the pandemic & 4.130 & 0.813 \\
\hline $\begin{array}{l}\text { Communication for overcoming organizational } \\
\text { emerged during pandemic }\end{array}$ & 4.290 & 0.778 \\
\hline
\end{tabular}

Source: authors' analysis.

\section{RESULTS}

First, we tested the data for the assumptions for linear regression and afterwards a hierarchical regression analysis was performed.

The assumptions of linearity, independence of errors and homoscedasticity were met. In regard to the normality assumption, it can be noted that plots indicate that the residuals are not perfectly normally distributed, which is a common problem in social science research (Hair et al., 1995). Additionally, this problem might be a result of the sample size. In the table below we represent the values of the both measures of multicollinearity (Tolerance and VIF) in order to demonstrate that the assumption of non-existence of multicollinearity is met. As presented in the Table 5, all the tolerance values are greater than 0.5 (the lowest is 0.576 ). The variance inflation factor (VIF) is simply the reciprocal of tolerance and in regarding to its interpretation it can be noted that when VIF is greater than 2 is usually considered problematic (the highest value in the table below is 1.737). 
Table 5 Measures of multicollinearity

\begin{tabular}{lcc}
\hline Variable & Tolerance & VIF \\
\hline Gender & 0.911 & 1.098 \\
\hline Age & 0.876 & 1.141 \\
\hline Position (doctor) & 0.731 & 1.369 \\
\hline Financial Benefits & 0.614 & 1.629 \\
\hline Support for implementing workplace guidelines & 0.609 & 1.642 \\
\hline Access to information regarding the pandemic & 0.614 & 1.629 \\
\hline $\begin{array}{l}\text { Communication for overcoming organizational issues } \\
\text { emerged during pandemic }\end{array}$ & 0.576 & 1.737 \\
\hline
\end{tabular}

Source: authors' analysis.

The results from the hierarchical multiple regression analysis where the dependent variable is Employees' satisfaction of HRM are presented in Table 6.

Table 6 Results from performed hierarchical multiple regression

\begin{tabular}{|c|c|c|c|c|}
\hline \multirow[t]{2}{*}{ VARIABLE } & \multicolumn{2}{|c|}{ Model 1} & \multicolumn{2}{|c|}{ Model 2} \\
\hline & B & Sig & B & Sig \\
\hline \multicolumn{5}{|l|}{ STEP 1 } \\
\hline Gender & 0.274 & 0.299 & 0.393 & 0.081 \\
\hline Age & -0.021 & 0.844 & -0.059 & 0.510 \\
\hline Position (doctor) & 0.381 & 0.153 & 0.322 & 0.166 \\
\hline Financial Benefits & 0.571 & 0.000 & 0.250 & 0.100 \\
\hline \multicolumn{5}{|l|}{ STEP 2} \\
\hline $\begin{array}{l}\text { Support for implementing workplace } \\
\text { guidelines }\end{array}$ & & & -0.216 & 0.280 \\
\hline $\begin{array}{l}\text { Access to information regarding the } \\
\text { pandemic }\end{array}$ & & & 0.459 & 0.004 \\
\hline $\begin{array}{l}\text { Communication for overcoming } \\
\text { organizational issues emerged during } \\
\text { pandemic }\end{array}$ & & & 0.607 & 0.000 \\
\hline $\mathbf{R 2}$ & 0.235 & & 0.477 & \\
\hline Change in R2 & 0.235 & & 0.243 & \\
\hline Adjusted R2 & 0.195 & & 0.428 & \\
\hline Durbin-Watson & & & & 1.928 \\
\hline
\end{tabular}

Source: authors' analysis.

Both models are statistically significant since the F-statistics for both models are statistically significant. Model 1 includes only the control variables which cover: age, gender and financial benefits and the explanatory power of this model is $19.5 \%$. By adding the block of 3 additional independent variables (directly connected with activities undertaken during the pandemic) the explanatory power of the model reaches $42.8 \%$. The Durbin-Watson statistics is 1.928 which means that there is no significant level of autocorrelation.

Model 1 indicates that providing financial benefits is positively and significantly related to employee's satisfaction of HRM $(p<0.01)$ and that the other control variables do not have statistically significant relation with the dependent variable.

In Model 2 where we add additional variables, the association between providing financial benefits and employee's satisfaction from HRM becomes statistically insignificant. On the other hand, the association between communication for overcoming organizational issues emerged during the pandemic and the employee's satisfaction from HRM is positive and statistically significant $(\mathrm{p}<0.01)$. Also, the relation between access to information regarding the pandemic and employee's satisfaction of HRM is positive and statistically significant at level $\mathrm{p}<0.05$. In Model 2 the relation between support for implementing workplace guidelines and 
employee's satisfaction of HRM is not statistically significant. Furthermore, in this model the relation of gender and employee's satisfaction of HRM is statistically significant at level $p<0.1$.

\section{DISCUSSION}

Most of the studies regarding the human resource management in the Covid 19 period, and especially those focused on the healthcare sector, are qualitative and give insightful recommendations for further research. The literature review conducted give the foundation for identifying the key challenges of the healthcare organizations during the pandemic and the key activities from the area of human resource management that should be undertaken in order to address them. Therefore, we developed a framework in which we describe the activities from the human resource management that should be included in every step/phase of the process of adaptation to the new conditions imposed by the pandemic. Additionally, this study gives an overview of the antecedents of the job-satisfaction.

The investigation of the antecedents of the healthcare providers satisfaction is important because of the possible relationship between job-satisfaction and turnover, absence rates and employee productivity (Bechtold et al., 1980). In regard to the previous research of jobsatisfaction in the healthcare organisations, it can be noted that Lock and Crawford (2001) and Giauque (2014) have used the same statistical method regression in investigating the antecedents of job-satisfaction in healthcare organizations (this method is also used in this study). Elsafty and Ragheb (2020) have been using correlation analysis to investigate which factors influence the retention of employees in Covid 19 pandemic in medical supplies sector and recommend that a proper communication should have been an important tool, especially in pandemic. Lock and Crawford (2001) have investigated the relation between organizational culture and subculture, and job satisfaction and commitment, and have found that managers need to focus more on organizational subcultures in generating greater commitment among employees. Moreover, Lock and Crawford (2001) have found that innovative sub-cultures have the strongest positive effect on commitment, while a bureaucratic sub-culture had a negative effect on commitment. Additionally, their findings indicate that supportive sub-culture, although positively correlated with commitment, did not have a significant independent effect on commitment after having controlled for the other independent variables in the study (p.609). Giauque (2014) has used the person-environment (P-E) fit approach for investigating antecedents of job satisfaction, organizational commitment and stress in public hospitals and found that P-E fit dimensions have differentiated effects on its dependent variables (they are considering P-E fit as a multidimensional concept with several sub-dimensions). In the empirical part, this study is trying to investigate how the identified activities for strategic human resource management in the healthcare sector influence the employees' satisfaction of HRM. The findings are indicating that communication for overcoming organizational issues emerged during the pandemic and access to information regarding the pandemic have positive and statistically significant influence on the employees' satisfaction of the human resource management in the healthcare organizations. The variable for providing financial benefits although has positive and statistically significant influence on the employees' satisfaction of HRM in the first model, did not have a significant independent effect when adding the second block of independent variables.

Overall, the paper is trying to make contribution by: identifying the key challenges for human resource management in the healthcare organizations during the pandemic, creating a framework for strategic human resource management in healthcare organizations during the pandemic and trying to empirically test how certain HR activities/practices influence the employees' satisfaction of the human resource management in the healthcare organization in North Macedonia. It is important to note that this study is trying to investigate the antecedents 
of employees' satisfaction of a single process (of the human resource management and not the general job-satisfaction) in a given context (in the healthcare organization during the Covid 19 pandemic).

\section{CONCLUSION}

The main findings of the study regarding the process of human resource management during Covid 19 pandemic indicate that key challenges faced by the managers and HR professionals in healthcare organizations included in this process can be summarize as follows: the erosion of "fit", work overloads, inconsistent guidelines, health related and quality of life issues, retention of medical staff. The proposed framework of strategic human resource management in healthcare organizations during the pandemic implies that the key issues of human resource should be analyzed in every step of the process. The most important activities for proper management of the healthcare providers in healthcare organizations during the pandemic include: evaluating the key capabilities of the staff beyond the basic skills (such as capacity for collaboration, adaptation, proactive behavior) (in the step of scanning the environment), then defining and understanding the key changes that had to be implemented in order to adapt to the newly arisen conditions and the main implications for healthcare staff, identifying the key activities for increasing staff preparedness and motivation for adaptation and for upcoming changes, as well as identifying the key employees for leading the process and effective support of the adaptation and implementation of the required changes through proper communication of organizational issues, asses to information regarding the pandemic and support for implementing workplace guidelines. This model offers a dynamic approach to strategic HRM during the pandemic (since the information accumulated in each of the phases should be transferred and adequately used in the other phases/steps), and explains how the roles of human resource management in healthcare organizations have evolved in the context.

Significant number of theories have given explanation about the influence of the features of the work environment on the job attitudes which can be used as foundation for investigating the employees' satisfaction from a single process (such as the human resource management process). The findings of the empirical part of the study are indicating that communication for overcoming organizational issues emerged during the pandemic and access to information regarding the pandemic have positive and statistically significant influence on the employees' satisfaction of the human resource management in the healthcare organizations. The variable for providing financial benefits although has positive and statistically significant influence on the employees' satisfaction of HRM in the first model, did not have a significant independent effect when adding the second block of independent variables. This study is trying to investigate the antecedents of employees' satisfaction of a single process (of the human resource management and not the general job-satisfaction) in a given context (in the healthcare organization during the Covid 19 pandemic). The explanatory power of the Model 2 in the hierarchical regression is $42.8 \%$, which is satisfying.

\section{LIMITATIONS AND FURTHER RESEARCH}

The purpose of the paper is to shed some light on the most important human resource practices during the Covid 19 pandemic and to understand how healthcare organizations had to rethink their approaches in order to maintain the motivation and commitment of the healthcare providers. However, this study has several limitations. Other factors related to strategic human resource management in the healthcare organizations, and also some specific factors related to the context in our country could be added. As for the empirical part, in the further research the approach towards designing and administering the questionnaire may be different, from mixing the order of the questions to using different scale types. Some variables may be designed as 
latent variables (with several items). Additionally, the finding of the study must be seen with caution, especially when interpreting the relation between the independent variables and the dependent variable having in mind the problem with the distribution of the residuals. Furthermore, the sample size is also a limiting factor. However, this paper attempts to quantify the relations, although most of the previous studies on human resource management and strategic human resource management during the Covid 19 pandemic has been explanatory and qualitative.

\section{REFERENCES}

Abdullah, M. I., Huang, D., Sarfraz, M., Sadiq, M. W. (2021), "Service Innovation in Human Resource Management During COVID-19: A Study to Enhance Employee Loyalty Using Intrinsic", Frontiers in Psychology, Vol.12, available at: doi: 10.3389/fpsyg.2021.627659.

Ajzen I. (1991) "The theory of planned behavior", Organizational Behavior and Human Decision Processes, Vol.50, No.2, pp.179-211.

Brugha, R. (2021), "Doctor Retention in a COVID-World: An Opportunity to Reconfigure the Health Workforce, or "Plus ça change plus c'est la meme chose"? A Response to the Recent Commentaries", International Journal of Health Policy and Management, available at: 10.34172/IJHPM.2021.60.

Carnevale, J. B., Hatak, I. (2020), "Employee adjustment and well-being in the era of COVID19: Implications for human resource management", Journal of Business Research, Vol. 116, pp. 183-187.

Center for public health of Republic of North Macedonia/Институт за јавно здравје на Република С. Македонија (2020), Кадар во здравствени установи во Република С. Македонија во 2019, Скопје, available at: http://iph.mk/wp-content/uploads/2021/01/Kadar2019-MK.pdf.

Collings, D, G., McMackin, J., Nyberg, A.J., Wright, P. M. (2021)," Strategic Human Resource Management and COVID-19: Emerging Challenges and Research Opportunities", Journal of Management Studies, available at: doi: 10.1111/joms.12695 [Epub ahead of print].

Elsafty, A., Ragheb, M. (2020), "The Role of Human Resource Management Towards Employees Retention During Covid-19 Pandemic in Medical Supplies Sector - Egypt", Business and Management Studies, Vol. 6, No.2, pp.50-59, available at: https://doi.org/10.11114/bms.v6i2.4899.

Fairbrother, K., Warn, J. (2003), "Workplace dimensions, stress and job satisfaction”, Journal of Managerial Psychology, Vol. 18, No.1, pp. 8-21.

Fiedler, F.E. (1967), A theory of Leadership Effectiveness, McGraw-Hill.

Fottler, M. D. (2011), "Strategic human resource management" in Fried, B., Fottler, M. D. (Ed.), Fundamentals of Human Resource, Health Administration Press, Chicago.

Fritzsche, B. A., Parrish, T. J. (2005), "Theories and Research on Job Satisfaction", in Brown, S. D., Lent, R. W. (Ed.), Career Development and Counseling: Putting Theory and Research to Work, John Whiley \& Sons, New Jersey.

George, J. M. (1992), "The role of personality in organizational life: issues and evidence". Journal of Management, Vol. 18, No.2, pp.185-213.

Giauque, D., Resenterra, F, Siggen, M. (2014), “Antecedents of Job Satisfaction, Organizational Commitment and Stress in a Public Hospital: a P-E Fit Perspective", Public Organization Review, Vol. 14, No. 2, pp. 201-228.

Gordon, A., Lyons, C., Rao, S., Finoli, L. (2020), "Health Care Workers' Challenges in the Care of a COVID-19 Patient", Critical Care Nursing Quarterly, Vol. 43, No. 4, pp. 400-406. Hackman, J. R., Oldham, G. R. (1976), "Motivation through the design of work: Test of a theory", Organizational Behavior and Human Performance, Vol. 16, No. 2, pp.250-279. 
Hair, J. F., Anderson R. E., Tatham, R. L., Black, W. S. (1995), Multivariate Data Analysis with Readings (1st ed.). Prentice-Hall, London.

Humphries, N., Creese, J., Byrne, J. P., Connell, J. (2021), "COVID-19 and doctor emigration: the case of Ireland", Human Resources for Health, Vol. 19, Art. No.29, available at: https://doi.org/10.1186/s12960-021-00573-4.

Ichsan, R. N., Khaeruman, S.S., Shara, Y., Liriwati, F. Y (2020), "Investigation of Strategic Human Resource Management Practices in Business after COVID-19 Disruption", Palarch's Journal Of Archaeology Of Egypt/Egyptology, Vol. 17, No.7, pp. 13098-13110.

Jamebozorgi, A. H., Agoush, L., NooriHekmat, S., Shokri, A., Sadatmoosavi, A., Shirvani, M., Hasanikaboutarkhani, M., Zare, Z. (2021), "Coronavirus and Its Impacts on Health Workers Retention: A Systematic Review and Meta-Synthesis", Research Square (preprint), available at: Coronavirus and Its Impacts on Health Workers Retention: A Systematic Review and MetaSynthesis | Research Square, DOI: 10.21203/rs.3.rs-220298/v1.

Judge, T. A., Hulin, C. L., Dalal, R. S. (2012), "Job satisfaction and job affect" in Kozlowsk, S.W.J. (Ed.), The Oxford Handbook of Organizational Psychology, e-publication available at:https://www.oxfordhandbooks.com/view/10.1093/oxfordhb/9780199928309.001.0001/oxfo rdhb-9780199928309-e-15.

Judge, T. A., Locke, E. A. (1993), "Effect of dysfunctional thought processes on subjective well-being and job satisfaction", Journal of Applied Psychology, Vol.78, No. 3, pp. 475-490.

Khatri, N., Pasupathy, K., Hicks, L.L. (2015), "The crucial role of people and information in health care organizations" in Fottler, M. D., Khatri, N., Savage, G. T (Ed.), Strategic Human Resource Management in Health Care. Published online: 10 Mar 2015, pp. 195-211, available at: https://www.emerald.com/insight/publication/doi/10.1108/S1474-8231(2010)9.

Lok, P., Crawford, J. (2001), "Antecedents of organizational commitment and the mediating role of job satisfaction", Journal of Managerial Psychology, Vol. 16, No.8, pp. 594-613.

Ness, M.M., Saylor, J., Di Fusco, L. A., Evans, K. (2020), "Healthcare providers' challenges during the coronavirus disease (COVID-19) pandemic: A qualitative approach", Nursing and Health sciences, Vol. 23, No.2, pp. 389-397.

OECD (2021), The COVID-19 crisis in North Macedonia, available at: THE COVID-19 CRISIS IN NORTH MACEDONIA (oecd.org).

Rangachari, P., Woods, J. L. (2020), "Preserving Organizational Resilience, Patient Safety, and Staff Retention during COVID-19 Requires a Holistic Consideration of the Psychological Safety of Healthcare Workers", International Journal of Environmental Research and Public Health, Vol. 17, No.12, available at: doi:10.3390/ijerph17124267.

Salancik, G. Pfeffer, J. (1978), "A Social Information Processing Approach to Job Attitudes and Task Design", Administrative Science Quarterly, Vol. 23, No.2, pp. 224-253.

Sengupta, M., Roy, A., Ganguly, A., Baishya, K., Chakrabarti, S., Mukhopadhyay, I. (2021), "Challenges Encountered by Healthcare Providers in COVID-19 Times: An Exploratory Study", Journal of Health Management, Vol. 23, No.2. pp. 339 -356.

Staw, B.M, Cohen-Carash, Y. (2005), "The dispositional approach to job satisfaction: more than a mirage, but not yet an oasis", Journal of Organizational Behavior, Vol. 26, pp.59-78.

Stuart, M., Spencer, D. A., McLachlan, C. J., Forde, C. (2021), "COVID-19 and the uncertain future of HRM: Furlough, job retention and reform", Human Resource management Journal, available at: https://doi.org/10.1111/1748-8583.12395.

Thompson, J.M., Buchbinder, S. B., Shanks, N.H. (2012), "An Overview of Healthcare Management", in Buchbinder, S. B., Shanks, N.H. (Ed.), Introduction to Healthcare Management, Jones and Bartlett Learning, Burlington.

Weiss, H. M., Cropanzano, R. (1996), “Affective Events Theory: A theoretical discussion of the structure, causes and consequences of affective experiences at work", Research in Organizational Behavior, Vol. 18, pp.1-74. 